\title{
O conhecimento taxonômico na obra elementos de botânica geral e médica
} (1877), De joaquim monteiro caminhoá

\section{Taxonomic knowledge in the work elements of general and medical botany (1877), By joaquim monteiro caminhoá}

DOI: $10.46814 /$ lajdv3n4-068

Recebimento dos originais: 01/05/2021

Aceitação para publicação: 31/06/2021

\author{
Alex Gonçalves Varela \\ Professor Adjunto da Universidade do Estado do Rio de Janeiro (UERJ) \\ Endereço Institucional: Rua São Francisco Xavier, 524, Maracanã, Rio de Janeiro, Brasil. CEP.: \\ 20550-900. \\ E-mail: alexvarelarj@terra.com.br \\ Sharleny Pereira De Almeida \\ Graduanda da Universidade do Estado do Rio de Janeiro (UERJ) \\ Endereço Institucional: Rua São Francisco Xavier, 524, Maracanã, Rio de Janeiro, Brasil. CEP.: \\ 20550-900. \\ E-mail: sharlenypereira@gmail.com
}

\begin{abstract}
RESUMO
Joaquim Monteiro Caminhoá (1836-1896) foi um dos mais atuantes cientistas do Império do Brasil. Contudo, sua trajetória enquanto estudioso da Botânica ainda não foi devidamente estudada, e as suas produções científicas ainda não foram analisadas criticamente de forma densa. Temos como objetivo analisar a obra Elementos de Botânica Geral e Médica, de autoria de Joaquim Monteiro Caminhoá, publicada em 1877, em particular o capítulo intitulado Taxonomia, que integra o volume número dois, e a sua contribuição para o processo de emergência e consolidação das ciências naturais no Império do Brasil.
\end{abstract}

Palavras-Chaves: Joaquim Monteiro Caminhoá, História das Ciências, Botânica, Império do Brasil.

\begin{abstract}
Joaquim Monteiro Caminhoá (1836-1896) was one of the most active scientists of the Brazilian Empire. However, his trajectory as a Botany scholar has not yet been properly studied, and his scientific productions have not yet been critically analyzed in a dense manner. Our objective is to analyze the work Elements of General and Medical Botany, by Joaquim Monteiro Caminhoá, published in 1877, in particular the chapter entitled Taxonomy, which integrates volume number two, and its contribution to the process of emergence and consolidation of natural sciences in the Empire of Brazil.
\end{abstract}

Key-words: Joaquim Monteiro Caminhoá, History of Sciences, Botany, Brazilian Empire.

\section{INTRODUÇÃO}

Temos como objetivo analisar a obra Elementos de Botânica Geral e Médica, de autoria de Joaquim Monteiro Caminhoá, publicada em 1877, em particular o capítulo intitulado Taxonomia, que 
integra o volume número dois, e a sua contribuição para o processo de emergência e consolidação das ciências naturais no Império do Brasil.

Joaquim Monteiro Caminhoá (1836-1896) foi um dos mais atuantes cientistas do Império do Brasil. Ele graduou-se em medicina pela Faculdade de Medicina da Bahia no ano de 1858, e realizou o seu doutorado na mesma instituição. A seguir, ingressou no Corpo de Saúde da Armada, prestando serviços como segundo cirurgião atuando em hospitais e navios. Foi professor da Cadeira de Botânica e Zoologia da Faculdade de Medicina do Rio de Janeiro (FMRJ), e da cátedra de história natural no Internato do Imperial Colégio de Pedro II. Foi sócio de inúmeras sociedades científicas nacionais e estrangeiras, como a Academia Imperial de Medicina, a Associação Brasileira de Aclimação, a Academia Brasileira de Medicina Militar, a Sociedade de Botânica da França, e a Sociedade de Ciências Naturais de Edimburgo. Foi membro adjunto da comissão brasileira na Exposição Universal de Viena, realizada de maio a novembro de 1873. Publicou inúmeros artigos e livros, dentre os quais salienta-se a obra Elementos de Botânica Geral e Médica, cuja primeiro volume foi publicado em 1877 seguido por mais dois números.

Gostaríamos de salientar que partilhamos das ideais que questionam o postulado de que a ciência moderna é

em larga medida olhada como o paradigma de um discurso hegemônico do poder ocidental, uma formação discursiva através da qual o resto do mundo está ao mesmo tempo subjugado e relegado ao controle do Outro binário. Deste ponto de vista, a difusão da ciência ocidental seria conseguida graças à imposição de práticas "racionais" a outras culturas "a-científicas'. (RAJ, 2007, p. 155)

Ao questionar que a difusão da ciência moderna decorre essencialmente das racionalidades das suas proposições, seguimos o olhar sobre a história das ciências para lá do horizonte europeu, fato que nos apresenta realidades complexas e mais sutis, uma vez que para além da Europa há "diferentes formações historicamente constituídas, com especificidades próprias”. (Idem. Ibidem, p. 156)

Longe de ser uma tábula rasa, ou um grande vazio científico, o Império do Brasil era um espaço de produção das ciências, onde se procedia correntemente à Botânica e aos levantamentos de plantas assim como à produção de textos e manuais. Deste ponto de vista, os fins e os conhecimentos botânicos não eram muito diferentes daqueles que eram conhecidos no mundo europeu na mesma época, e eram partilhados e seguidos conforme eram por lá praticados. Portanto, não podemos considerar que a ciência é um "produto puramente ocidental, a linha de separação por excelência entre a Europa e o resto do mundo. (...) A história das práticas científicas ditas ocidentais ultrapassa as fronteiras da Europa e se mistura inextricavelmente com a história das práticas eruditas de outros povos, noutras regiões". (Idem. Ibidem, p. 176) 
Estamos assim preocupados em observar a produção local do conhecimento botânico durante o século XIX no Brasil, por meio da publicação já supracitada, manual que era utilizado por Caminhoá em suas lições na FMRJ, ou no Imperial Colégio de Pedro II. Observaremos quais os autores que ele mencionou e aqueles que refutou ou criticou, as idéias botânicas que partilhou, os sistemas de classificação dos vegetais que ,mencionou ou utilizou, entre outras questões. Portanto, é para essa natureza cada vez mais local do conhecimento, as contingências e especificidades locais, a produção dos conhecimentos em seu ambiente específico que estaremos olhando, e assim, conforme já comentamos nos afastando "da visão tradicional da ciência em contexto histórico-mundial, universalmente válida". (RAJ, 2015, p. 165)

Convém salientar que seguimos uma abordagem contextualista, uma vez que buscamos articular a produção do conhecimento com o contexto social em que o mesmo foi gestado. Ao realizarmos uma leitura contextualizada da referida obra de Caminhoá, poderemos observar quais as questões que ele formulava, os argumentos que apresentou, e em que medida aceitavam e se apropriavam, ou contestavam ou repeliam, ou às vezes até ignoravam as idéias então dominantes no debate científico da época, sobretudo no campo das ciências botânicas. O texto também permitirá observar quais as obras lidas e analisadas pelo estudioso. Portanto, será com base no contexto em que ele escrevia, que a sua produção científica será analisada, uma vez que são “construídos segundo regras variáveis no tempo e no espaço social, um objeto que seria ingênuo considerar transparente em si mesmo, como se relatasse fatos brutos". (PESTRE, 1996, p. 37)

O ingresso de Caminhoá na FMRJ se dá no contexto da década de setenta do século XIX, momento em que as elites médicas da Corte passaram a perseguir e discutir o movimento de reforma institucional. Tais reformas foram operadas com o Decreto de 19 de abril de 1879, a chamada reforma Leôncio de Carvalho, resultando na introdução da liberdade de ensino e do ensino prático das disciplinas médicas, alterando profundamente a FMRJ, e acabando por possibilitar o aparecimento de outros centros de produção e reprodução dos conhecimentos baseados no mesmo modelo de medicina. Figurino alemão. (EDLER, 2014, pp. 61-62)

De acordo com informações contidas no verbete "Escola Anatômica, Cirúrgica e Médica do Rio de Janeiro",

as disposições da reforma Leôncio de Carvalho, que ainda não tinham sido executadas, foram ampliadas pelos decretos $n^{\circ} 8.024$ de 12 de março de 1881 e $n^{\circ} 3.141$ de 30 de outubro de 1882, e colocadas em execução por ordem dos Ministros do Império, Rodolpho Epiphano de Souza Dantas, e Pedro Leão Velloso. Ainda segundo o supra verbete, "conforme o decreto $n^{o}$ 3.141 o número de disciplinas do curso médico foi aumentado para 26 com a incorporação de novas cátedras em seu currículo (...) O curso odontológico foi instituído. Alteraram-se as normas que regiam os exames e o ensino prático recebeu novo impulso com a criação de 14 laboratórios e a nomeação de preparadores, assistentes e conservadores, categorias de funcionários até então inexistentes. 
(CASA DE OSWALDO CRUZ/FIOCRUZ, 17/06/2021, p. 5)

Os Estatutos implantados pelo Decreto 9311 de 25 de outubro de 1884, na gestão do Conselheiro Vicente Cândido Figueira de Sabóia (1881-1889), diretor da Faculdade, consolidam as reformas encetadas pelos lentes, dando-lhes respaldo jurídico. Tais estatutos mantinham em linhas gerais o plano de Leôncio de Carvalho, com pequenas modificações. De acordo com Edler (2014, p. 10), os Estatutos de 1884 expressavam uma nova representação do saber médico, baseados no figurino germânico, que marcou a introdução dos estudos práticos das disciplinas clínicas e experimentais, e a quebra do monopólio da formação profissional pelas faculdades do Rio de Janeiro e de Salvador.

Por sua vez, salientamos que Caminhoá respira os ares da geração de 1870, cujos membros partilhavam a necessidade de uma intervenção política para formular uma crítica ao status quo imperial e apresentar um programa de reformas. Foi o que Alonso (2002) denominou de reformismo. A conjuntura política do Império em suas últimas décadas foi marcada por uma crescente insatisfação em relação a características sociais e políticas do sistema, como a escravidão, a centralização, a união da Igreja e do Estado, e a própria forma monárquica de governo. Os indivíduos dessa geração partilhavam a experiência comum de exclusão social e política, marginalização em relação aos postos políticos, aos empregos, aos negócios. Por partilhar dessa situação negativa formularam críticas às instituições, valores e práticas fundamentais do regime político dominante saquarema. E, para tal, foram buscar onde as pudessem encontrar os argumentos e justificativas para expressar seu dissenso e imaginar projetos de reformas.

Caminhoá está inserido nessa geração de 1870, respirando os ares desse momento de reformas. Ele era um letrado, que integrava as elites médicas da Corte, e estava inserido nas instituições científicas do Império, como a FMRJ, e, num segundo momento, o Imperial Colégio Pedro II. Nestes espaços ingressou por meio de concurso público. Cabe salientar que a conquista do emprego por meio do concurso era uma possibilidade de inclusão nessa sociedade, contudo a patronagem e as fraudes nos concursos dificultavam muitas vezes a inclusão. (Idem. Ibidem, p. 138)

Caminhoá está integrado ao conjunto dos professores da FMRJ. Eles não foram decisivos na mobilização da geração de 1870, mas também não foram irrelevantes. Foram sobretudo os professores igualmente insatisfeitos com o padrão de carreira e com o gênero de formação recebido, que se aventuraram por buscar criar novas cátedras de clínicas especializadas e a construção de diversos laboratórios compreendendo todo um amplo leque de novas disciplinas clínicas e experimentais, na Faculdade de Medicina. As palavras de ordem ensino prático e ensino livre defendidas pelas elites médicas, como salientou Edler (Op. cit, p. 189), “atingiram os pilares do modelo centralizador francês 
que inspirara a criação de todas as instituições médicas na fase de consolidação do Império Brasileiro. Tais inovações no cenário do ensino médico (...) ganharam aqui um novo significado".

Inserido nesse contexto histórico, Joaquim Monteiro Caminhoá foi um cientista que teve uma carreira consolidada e reconhecida nacional e internacionalmente. $\mathrm{O}$ estudioso se dedicou a produzir conhecimento científico sobre questões médicas e botânicas. Estamos nos dedicando a estudar a sua trajetória acadêmica, que ainda não foi devidamente estudada, bem como as suas produções científicas ainda não foram analisadas profundamente. Dessa forma, há lacunas que precisam ser preenchidas pelos estudiosos que se dedicam a pesquisar as relações ciências e trajetórias, e caminhos amplos e profícuos que merecem ser explorados e estimulam novas reflexões. (VARELA, 2019; 2021) Conforme já informarmos, a produção científica de Caminhoá que iremos analisar é o capítulo Taxonomia, que integra o conteúdo do volume II da obra Elementos de Botânica Geral e Médica (1877).

\title{
2 A OBRA ELEMENTOS DE BOTÂNICA GERAL E MÉDICA (1877)
}

A publicação "Elementos de Botânica Geral e Médica", a principal obra de Caminhoá, cujo primeiro volume, num total de três, foi publicado em 1877. Na Introdução da obra assim afirmou Caminhoá:

\begin{abstract}
Este livro é o resultado de quase dezesseis anos de estudo e meditação; é o resumo de cinqüenta e nove compêndios e obras de diversos autores da Europa, Estados Unidos, Chile, Brasil, até os publicados há pouco tempo; como o do professor Afonso Wood, de New York, por ocasião da festa do centenário da Independência Americana, o do professor Bellinck, de Namur, (na Bélgica), vindo à luz em fins de 1870; o do professor Darchartre, cuja última parte se acha ainda no prelo, a "História das Plantas" do professor Bailon (da faculdade de Medicina de Paris), a Flora Braziliensis do Dr. Martius, além de outros mais, cuja publicação ainda não está terminada. (CAMINHOÁ, Vol. 1, 1877, p. VII)
\end{abstract}

Caminhoá argumentou que a razão que o motivou a redigir tal obra foi o fato de reconhecer que existem obras de Botânica que são muito resumidas e "não tratam de certos assuntos que tenho por indispensáveis, e, portanto, não servem por compêndios nos cursos superiores", ou então são obras extensas, "como o do sábio professor Julio Sachs", que "tratam apenas de parte da ciência, e servem para ser consultadas de preferência pelos que, sabendo a matéria, desejam nela aperfeiçoar-se”. Assim, Caminhoá argumentou que elaborou um compêndio que estava "entre os primeiros e este do professor Sachs". (Idem. Ibidem, p. VII)

Caminhoá informou que a obra Class-Book of Botany, de J. H. Baifoar, professor da Universidade de Edinburgo, foi aquela que ele tomou como referência, embora dele se afastasse em 
alguns pontos. Dentre eles, no estudo das famílias ou ordens naturais, argumentou que exemplificou com plantas brasileiras.

Dentre os naturalistas e botânicos que Caminhoá agradeceu por terem apresentando comentários críticos à obra estão Adolpho Brogniart (1801-1876), Conde de Jaubert, Pierre Étienne Simon Duchartre (1811-1894), Henri Baillon (1827-1895), tendo deste último servido de referência a sua obra História das Plantas na parte fitográfica, e Ernest Germain de Saint Pierre (1815-1882).

Caminhoá informou que o público alvo da sua obra eram "os alunos das diferentes faculdades e escolas, os agricultores e amadores da Botânica". (Idem. Ibidem, p. IX) Contudo, argumentou o professor da FMRJ, ter empregado "uma linguagem ao alcance de qualquer inteligência". (Idem. Ibidem, p. X)

A utilização de estampas foi um dos destaques da obra, que segundo Caminhoá, são "meios de simplificar as explicações da História Natural e de torná-las facilmente compreensíveis". (Idem. Ibidem, p. X) Elas foram adquiridas junto à Casa Hachette \& Cia., em Paris, e que já tinham sido utilizadas em obras de outros autores. Utilizou também três mapas de geografia botânica. Assim, afirmou Caminhoá ter "seguido o exemplo de todos os botânicos, que, já encontrando feitas gravuras que lhes sirvam, embora já figuram noutras obras, fazem aquisição delas”. (Idem. Ibidem, p. XI) Assim, ele afirmou ter tornado "instrutivo, claro e nítido" o compêndio produzido.

O trabalho foi, segundo Caminhoá, apresentado e aprovado pela Faculdade de Medicina do Rio de Janeiro, e adotado como compêndio. ${ }^{1}$ E, foi também agraciado com o prêmio máximo concedido pelo Regulamento das Faculdades de Medicina do Império. Portanto, a publicação teve o apoio do governo imperial. Entre a aprovação e a publicação da obra passaram-se alguns anos. Tal fato possibilitou "retocálo- em alguns pontos, depois de tê-lo submetido à crítica de diferentes botânicos na Europa, os quais (...) não só me animaram, como aconselharam; e em alguns pontos fizeram-me conhecer o que a ciência tinha adiantado!”. (Idem. Ibidem, p. VIII-IX)

Caminhoá informou que o público alvo da sua obra era "os alunos das diferentes faculdades e escolas, os agricultores e amadores da Botânica”. (Idem. Ibidem, p. X) Contudo, argumentou o professor da FMRJ, ter empregado "uma linguagem ao alcance de qualquer inteligência". (Idem. Ibidem, p. X)

O Compêndio, além de uma Introdução ao Leitor, contém oito partes, que são: 1) Prolegômenos; 2) Fitotomia; 3) Organografia; 4) Fisiologia; 5) Fitologia ou Classificação; 6)

\footnotetext{
${ }^{1} \mathrm{O}$ parecer foi emitido na data de seis de fevereiro de 1873, pelos professores Ezequiel Correa dos Santos, José Thomaz de Lima, e Manoel Maria de Morais e Vale.
} 
Teratologia e Patologia; 7) Estudo da distribuição dos vegetais no globo terrestre (geologia e geografia vegetais); 8) dos herbários. Este último capítulo será a partir de agora o nosso objeto de análise.

\section{A PARTE INTITULADA TAXONOMIA}

O capítulo Taxonomia foi estruturado por meio de uma subdivisão em cinco itens, que seguem: Das classificações em Geral; Origem das Espécies; Das classificações em Particular; Nomenclatura Botânica; Métodos e Sistemas de Classificação.

No primeiro item intitulado Das Classificações em Geral, Caminhoá define a Botânica clássica como a ciência que estuda os vegetais a partir dos seus caracteres, colocando-os no lugar que devem ocupar na escala natural, fato que permite conhecer os seus usos e inúmeras utilidades.

O botânico argumentou que há uma quantidade imensa de plantas conhecidas. Em função de tal fato, ele alertou que se deve ter o cuidado de agrupar aquelas que se parecem muito entre si, e que apresentam determinado número de caracteres constantes, igualmente semelhantes. Frente à vasta diversidade, nasce importante e indispensável ideia das classificações, ultrapassando as barreiras da Botânica, já que compunha uma organização que facilitaria todo o estudo das ciências naturais.

Dando sequência, Caminhoá lança mão das distinções indispensáveis entre os seres naturais, e busca recordar os vocábulos empregados no estudo desta parte da Botânica, o que é denominado Taxonomia, e que alguns outros autores também chamam de Botânica Sistemática, ramificação responsável pelas leis gerais das classificações e de suas aplicações na Botânica.

Em primeiro momento, Caminhoá inicia definindo "indivíduo" como aquele ser ou tipo que não pode ser dividido, sem que resulte uma imperfeição e, pela reprodução, geram seres completamente iguais a si, o que para a História Natural denomina-se "espécie". O autor apresenta para nós que a ideia mais corrente e aceita da definição de espécie é "[...] a reunião de indivíduos que são tão semelhantes uns aos outros, como esses aos pais, e aos filhos, etc., e que se reproduzem por fecundação".(CAMINHOÁ, 1877, II, p. 1576). Informa que alguns autores defendem que cada indivíduo deva ser absolutamente distinto dos demais, e, portanto, constituem, cada um, uma espécie. Para esses autores, "a espécie é uma forma constante de indivíduos, que se reproduzem de sua semente". (Idem. Ibidem) De acordo com Caminhoá, "Isso é hoje completamente inaceitável; e só serve para dificultar as classificações e a acepção técnica da palavra espécie.” (Idem. Ibidem)

Ainda sobre a definição de espécie, o autor apresenta algumas definições de espécies que se aproximam e são norteadas pela crença no sentido de que essa categoria é composta por seres com características semelhantes e que possuem a capacidade de se reproduzir entre si para manter esses caracteres nas gerações seguintes. Ele apresentou definições de espécies baseadas na filiação, semelhança, e na filiação e semelhança. Ademais, informou que a maior parte das definições se faziam 
presentes nos trabalhos de Isidore Geoffroy Saint-Hilaire (1805-1861), principalmente em sua obra História Natural Geral dos Reinos Orgânicos (1854-1862).

Dentre as definições de espécies estão aquelas apresentadas pelos seguintes estudiosos: John Ray (1627-1705), Marie Jean Pierre Flourens (1794-1867), Joseph Pitton de Tournefort (1656-1708), Jean Théodore Lacordaire (1801-1870), Stephan Endlicher (1804-1849) e Franz Unger (1800-1870), Carl von Lineu (1707-1778), Georges-Louis Leclerc, conde de Buffon (1707-1788), Jean-Baptiste de Lamarck (1744-1829), Augustin Pyrame de Candolle (1778-1841), Georges Cuvier (1769-1832), Henri Marie Ducrotay de Blainville (1777-1850), Achille Richard (1794-1852), Alfredo Dugés (18261910), Robert Brown (1773-1858), Michel-Eugène Chevreul (1786-1889), Johannes Muller Argoviensis (1828-1896), Auguste de Saint-Hilaire (1779-1853), Julius von Sachs (1832-1897).

Joaquim Caminhoá argumentou que a idéia de espécie é capital, uma vez que dela depende a resolução de certo número de questões biológicas e filosóficas, gerando um intenso debate. ${ }^{2}$ Sobre tal discussão, que ultrapassa argumentos científicos, assim comentou:

Quem, desapaixonadamente, acompanhar as discussões, e apreciar os argumentos dos contendores de um e outro lado, verá que, no cabo de pouco tempo, uns, como os outros, deixam o terreno da História Natural, e vem emaranhar-se num Dédalo de hipóteses, que fálos chegar às regiões ultrafilosóficas, que não são, certamente, aquelas em que se discutem as coisas naturais, - que todas devem basear-se no visum et repertum. (Idem. Ibidem, p. 1577)

Em primeiro lugar, Caminhoá apresentou os defensores da pluralidade das espécies, aqueles cujos argumentos não se sustentam diante de fatos práticos incontestáveis, apresentados por seus adversários, e acabam por se socorrer na interpretação dos "Livros Sagrados", aí se fixando. Tais argumentadores, segundo Caminhoá, "não admitem aquilo que as Letras sagradas contrariam; e assim levam a questão para o lado da Fé; sem que tal seja preciso”. (Idem. Ibidem, p. 1577)

No campo oposto do debate, Caminhoá argumentou que estavam aqueles que observavam e interpretavam a natureza sem procurar "a decifração dos Livros Santos". Estes argumentadores sublinhavam que os intérpretes da Bíblia Sagrada condenaram Galileu Galilei por defender a teoria heliocêntrica, o oposto do que "resavam as letras mosaicas", e dizem que tais argumentos são "um subterfúgio dos pouco doutos em ciências naturais". (Idem. Ibidem, p. 1578)

Convém sublinhar que o entendimento sobre o conceito de espécie variou ao longo dos tempos. Seguindo os passos de Mayr (1998), os antigos não reconheciam a integridade biológica de cada espécie. Segundo o autor, Aristóteles admitia a ocorrência frequente da hibridação entre as espécies. Também admitia a crença folclórica de que as sementes de uma espécie de planta podiam germinar em plantas de outra espécie. Também não havia uma terminologia consistente com respeito à natureza das

\footnotetext{
${ }^{2}$ Sobre uma discussão acerca do conceito de espécie na obra de Joaquim Monteiro Caminhoá, ver: Santos (2017).
} 
espécies. Por sua vez, a adoção do cristianismo e a aceitação do dogma da criação pouco mudaram a situação no começo. Teríamos que aguardar a Reforma para que observássemos uma mudança drástica de atitude com relação às espécies. O dogma que passou a ser aceito era a da fixidez e a constância total das espécies. Se tornou consenso a partir de uma interpretação literal do Gênese exigir a crença na criação individual de cada espécie de plantas e de animais, nos dias que precederam à criação de Adão. Segundo Mayr, "a espécie era a unidade da criação”. (Idem. Ibidem, p. 199)

Ainda seguindo os argumentos de Mayr, a interpretação criacionista das espécies está em perfeito acordo com o conceito essencialista da espécie, segundo o qual cada uma delas se caracteriza por sua essência imutável e se separa de todas as outras por uma marcante descontinuidade. O essencialismo sustenta que a diversidade da natureza, tanto inanimada como orgânica, é o "reflexo limitado de universais imutáveis”. (Idem. Ibidem, p. 199)

Se para os essencialistas toda espécie é constante ao logo do tempo, para os nominalistas somente existem indivíduos, enquanto as espécies, ou qualquer outra "classe", são construções feitas pelo homem. De acordo com Mayr, o nominalismo, uma escola de filosofia medieval, rejeitava a noção do essencialismo, no sentido de coisas semelhantes compartilharem uma mesma substância (essência), e proclamava, em vez disso, que todas as classes de objetos similares compartilham, de fato, de um nome. Tal interpretação era aplicada também às espécies, por diversos autores do século XVIII. (Idem. Ibidem, p. 206) O conceito nominalista de espécie permaneceu popular entre os botânicos, ao longo de todo o século XIX. Para estes, a natureza produz indivíduos, e nada mais. As espécies não tinham uma existência real na natureza, são conceituações mentais.

As pesquisas de Charles Darwin (1809-1882) e Alfred Russell Wallace (1823-1913) trouxeram novidades para o entendimento do termo espécie. Em 27 de dezembro de 1831, o naturalista inglês realizou uma viagem ao redor do mundo a bordo do HMS Beagle, a qual proporcionou a coleta de dados e informações acerca do processo evolutivo e da origem das espécies. Após cinco anos, retornou, dedicando-se a várias investigações, onde procurou obter respostas acerca do mundo mecanismo natural que propiciava a mutação das espécies. Por sua vez, Wallace, de maneira análoga a Darwin, colheu dados e informações através de duas viagens para a América do Sul e para o Arquipélago Malaio. Carmo \& Bizzo \& Martins (2009, p. 230), informam que, além de ter acesso à biogeografia e diversidade biológica, ambos realizaram a leitura das mesmas sobras científicas. Eles refutaram os criacionistas, por entender que as espécies não são fixas. Para Darwin e Wallace, os animais e as plantas se modificavam no decorrer do tempo, produzindo novas raças e espécies.

Contudo, convém salientar, conforme registraram Carmo \& Bizzo \& Martins (2009, p.230), a maioria das pessoas, mesmo aqueles que detinham um conhecimento mais elevado, acreditava na imutabilidade das espécies, ou seja, que as espécies não se modificavam no decorrer do tempo. Muitos 
ainda acreditavam na narração da Sagrada Escritura, no livro do Gênesis, que relata que Deus criou o universo e as espécies como elas são atualmente, já adaptadas ao ambiente, e criou o homem à sua semelhança. Além disso, a maioria dos professores e amigos de Darwin também acreditava firmemente que as espécies não se modificavam, ou seja, acreditavam na imutabilidade das espécies.

Retornando a análise do texto, Caminhoá sublinhou que alguns religiosos versados no estudo da História Natural têm demonstrado que as interpretações do livro bíblico do Pentateuco não foram realizadas da forma mais correta. E, argumentam que não há "o suposto antagonismo entre as ciências naturais e o Livro Mosaico". (CAMINHOÁ, II, Op. cit., p. 1578)

Em combate à tal situação, Caminhoá destacou o trabalho de Jules Fabre d'Envieu (1821-1901), professor da faculdade de Teologia de Paris, autor de inúmeras obras, dentre as quais As Origens da Terra e do Homem Segundo a Bíblia, e Segundo a Ciência... (1873), afirmando que o teólogo prestou um trabalho relevantíssimo tanto à religião quanto à ciência, ao combater o materialismo, e a “ignorância de muitos sacerdotes, que, não sendo versados nem nas Ciências Naturais, nem nas línguas naturais, e não sabendo como se haverem, dão golpes mortais na verdade e na ciência". E, sublinhou Caminhoá:

\footnotetext{
Para que confundir o que é do domínio da matéria, e, portanto sujeito às leis especiais, com o que é do domínio psíquico?! Não compreendemos a razão de repugnar-se discutirfrancamente no terreno da História Natural!

Nada temos com as crenças em Ciências, nem buscaremos tudo explicar comodamente só pela vontade de Deus! (Idem. Ibidem, p. 1579)
}

A argumentação do abade sobre a relação entre ciência e religião, citando inclusive a Bíblia e algumas de suas passagens e capítulos, revela seu caráter de homem ilustrado, em que apresenta uma leitura crítica do "Livro das Saradas Escrituras", em particular do Gênesis.

Caminhoá entre as páginas 1579 e 1581 apresentou uma extensa nota de pé-de-página com trechos significativos da obra supracitada de d'Envieu. Caminhoá argumentou que o teólogo criticou o materialismo, e os ateus, e a seguir afirmou que houve "criações ante-genesianas". Assim d'Envieu argumentou sobre a tese da antiguidade da Terra, superando o relato bíblico:

A tese da antiguidade de alguma raça humana parece provada. Doutra parte, a Bíblia não se opõe á essa antiguidade; e eu não vejo dificuldade alguma para aceitá-la como um fato devidamente estabelecido. Admito, pois, que se deve conhecer a terra e a gênero humano a alta antiguidade que lhe atribuem os sábios contemporâneos. Reconhecerei, se quiserem, que o homem, que assistiu alguns dos fenômenos geológicos do período quaternário remonte a 250.00 anos.

A ciência pode chegar á demonstração geológica dessa teoria não me comoverá isso de modo algum... Quero mesmo crer, que encontraram-se vestígios da vida humana nos terrenos que precederam essas formações (quaternárias). Quanto a mim não me assustaria de modo algum por minha 
fé cristã, si descobrissem vestígios humanos em todos os terrenos anteriores ao diluvium... Essas afirmações estão sem duvida em descordo com as teorias imaginadas por numerosos teólogos, a propósito do texto mosaico. Mas esse desacordo provém de dar-se à narração sagrada uma interpretação exagerada,e, ouso dizê-lo, fantástica.

Os doutores e os teólogos têm comentando o texto da Gênese, sobretudo com o fim de tirar dela doutrinas morais. (Idem. Ibidem, 1579)

Seguindo os passos de d'Envieu, este argumenta que os comentares do texto bíblico têm apresentado um "sentido forçado ou evidentemente falso com detrimento do sentido literal" do primeiro capítulo. E, seria exatamente por tais interpretações, tomadas fora do texto, que a Gênesis é atacada. Assim argumentou: "Exagerando a narração bíblica, os comentadores a têm comprometido. Esforçando-se por introduzir no texto o maior numero possível de coisas, tem forçado a nota. É um erro: a exageração é um dos grandes flagelos da apologética”. (Idem. Ibidem, p. 1579)

E, a seguir, d'Envieu informa o que a Bíblia de fato nos possibilita conhecer:

\begin{abstract}
A Bíblia nos dá, é verdade, conhecimentos sobre uma certa organização da terra, assim como sobre a formação e sobre a origem real do gênero humano atual. Mas os intérpretes do primeiro capítulo do Gênese, se enganam quando apresentam essas páginas inspiradas como resolvendo todas as questões interessantes que estão fora da narração, e que a ciência contemporânea tem abordado.

(...) A explicação mais natural do texto sagrado, que julgamos tê-la demonstrado neste livro, autoriza a admitir como possível a existência de um ou de muitos mundos anti-adâmicos. Nada nos proíbe a Escritura Santa de crermos em criações anteriores àquelas, cuja narração faz a gênese. Nós podemos admitir, que, muito antes da semana genésica, a terra existia e tinha sido habitada por seres organizados como nós. Não se pode, baseando-se na Bíblia, negar a existência ou a antiguidade de uma raça de homens. Este santo Livro não se opõe a que se recue a uma distancia incomensuravelmente afastada de nós, o aparecimento das diversas raças humanas sobre a terra. (Idem. Ibidem, p. 1580)
\end{abstract}

O abade francês apresenta uma profunda crítica daqueles que entendem que não se pode raciocinar e interpretar a Bíblia, a qual já tem sido bastante estudada e meditada, e, que, tudo já foi dito sobre "dogmas, como sobre a história e a literatura hebraicas". Em outras palavras, não haveria mais nada a se dizer sobre os textos bíblicos, estando esgotados os comentários. Aí reside exatamente a crítica do religioso, ao afirmar que o "estudo da Escritura Sagrada é ainda hoje fértil em soluções novas e interessantes para todo espírito que quer aprofundar os documentos revelados". (Idem. Ibidem, pp. 1580-1) E, seguindo o pensamento do religioso, as novas interpretações devem

conservar o sentido das palavras empregadas nos dois primeiros versículos do primeiro capítulo da Gênesis; e todo capítulo ficará em sua relação com a Geologia, a Paleontologia, e a Arqueologia Pré-histórica. Veremos que assim as revelações mosaicas estão, para uma grande parte ao menos, fora da arena em que disputam os sábios. Ser-nos-á depois fácil demonstrar que, relativamente a todo o resto as tradições contidas na Bíblia, não estão em contradição nem com os dados fundamentais da razão, nem com o que ensinam as ciências modernas. (Idem. Ibidem, p. 1581) 
Portanto, para d'Envieu, ciência e religião não são espaços conflituosos. Se complementam, e podem auxiliar uma a outra no modo de entender o mundo e a sua natureza. São esferas distintas, mas os princípios religiosos podem contribuir para a transformação do conhecimento. Não considera a religião como um obstáculo para o desenvolvimento científico.

Caminhoá assim justificou a razão de ter apresentado tão longa nota sobre as considerações de d'Envieu:

Esta longa nota tem por fim mostrar, que andam errado os que acreditam, que é contra a religião o sustentar as modernas doutrinas em ciências naturais. Não queremos que se seja materialista em matérias de religião e filosofia, nem se apele para os espíritos em matéria positiva de História natural. (Idem. Ibidem, p. 1581)

Finalizado o primeiro item, passamos ao segundo que se intitula Origem das Espécies. Este assunto, para Caminhoá, é o de máximo interesse, já que foi a base da resolução para inúmeros dos problemas biológicos e filosóficos. O botânico argumentou que há várias obras sobre o assunto, e cada uma delas o trata de diversas formas. E, informa que todas as teorias e sub-teorias sobre o tema resumem-se em duas: criação independente e evolução. Aquela é mais antiga e admite para cada tipo um germe ou par, sem se preocupar com questões e objeções biológicas. Por sua vez, a segunda defende que de apenas um ou alguns germes originaram-se as espécies passadas, presentes e futuras. É a mais moderna teoria e tem como referência Charles Darwin e demais naturalistas.

$\mathrm{O}$ autor argumentou que nenhuma das duas teorias está isenta de receber objeções. Na da criação, se apresentam os inúmeros fatos de modificações profundas de distintas espécies, que se transformaram umas em outras. Em relação à evolução, Caminhoá revela que há sérias críticas que demonstram que, apesar do passar dos séculos, os gêneros e as espécies que possuem um crescimento espontâneo em determinadas zonas continuam sendo os mesmos. Ademais, as sementes que foram transportadas até regiões muito diferentes, se reproduziram do mesmo modo.

Outra objeção, segundo Caminhoá, é a que se baseia na lei do atavismo. Em virtude de tal lei, o ser, modificado pelas condições climáticas, nutritivas, entre outras, torna-se primitivo novamente em um período mais ou menos curto. Dessa maneira, conclui-se que só por meio de artifício na cultura é que se torna possível modificar os seres vivos, a ponto de aparecerem espécies novas.

Caminhoá argumentou que as investigações no campo científico prosseguem, e assim aguardamos "as provas e experimentos capazes de trazer a evidência". (Idem.Ibidem, p. 1582) Contudo, ressaltou novamente o autor que não se deve confundir as questões religiosas com as do conhecimento. E, teceu o seguinte comentário: 
Que importa ao cristão que todos os seres tivessem por origem um germe, ou uma célula, ou que cada um tivesse tido seu germe?! História Natural não é Ontologia; ela não deve servir para fazer-se propaganda anti-religiosa ou religiosa; e quando tal sucede, ela se acha deslocada.

A origem primitiva de todas as coisas foi, é, e será um mistério; portanto, nos ocupamos aqui do que não é misterioso; porém visível e demonstrável. O norte do verdadeiro naturalista é o visum et repertum!" (Idem. Ibidem, p. 1582).

Caminhoá argumentou que, tomando como base as palavras de Alexandre Von Humboldt, o homem ao interrogar a natureza não se contenta apenas em observá-la, mas objetiva que nasçam fenômenos sob condições determinadas. Ao colher e registrar os fatos, para aprofundar a investigação, a filosofia da natureza se despe das formas mais vagas e poéticas e assume um caráter mais rígido, em que pesa o valor das observações. Não há mais adivinhações, mas combinações e raciocínios. E, assim comentou sobre o proceder do naturalista:

Já vedes, que o naturalista, quando entra nos profundos estudos d'esta importante parte da Botânica, precisa basear-se em fatos positivos, para poder interpretar os seres criados, $e$ dispô-los em ordem; cada um ocupando seu lugar na escada; precisa ter de um e de outro lado os tipos que, por seus caracteres, mais se aproximam deles!. (Idem. Ibidem, p. 1583)

De acordo com Caminhoá, a História Natural é uma das áreas do conhecimento mais difíceis e confusas, portanto, não se pretende acrescentar coisas novas, apenas simplificá-la. Conforme já havia mencionado no início do estudo, os taxonomistas e os fitografistas cumpriram o papel de agrupar as plantas de acordo com certos caracteres, entre os quais sobressai a semelhança constante entre elas. A partir disso, os indivíduos que possuem essa semelhança entre si, e que são nascidos dos mesmos pais são denominados espécies.

Prosseguindo, Caminhoá argumentou que daquelas espécies que oferecem caracteres menos comuns, que as fazem aproximar-se de outras espécies, a esses grupos de distintas espécies parecidas umas com as outras se dá o nome de gênero. Por sua vez, os diferentes gêneros apresentam alguns caracteres comuns entre os mesmos, principalmente no que se refere ao ovário e à flor. Tal constatação levou à criação da família ou ordem, que segundo definição do botânico, é "a reunião de gêneros semelhantes". (Idem. Ibidem, p. 1584) Algumas famílias apresentam, às vezes, caracteres que condicionam o naturalista a agrupá-la em classes. Estas, sob o ponto de vista da presença das cotilédones, ainda oferecem o natural agrupamento em ramos. Por fim, o conjunto de ramos constitui o reino vegetal.

Caminhoá prosseguiu considerando que os órgãos e funções dos seres do reino vegetal são análogos por seus caracteres aos dos animais. Como as plantas, eles vivem e são dotados de órgãos. Os elementos do mundo vegetal e animal pertencem ao império orgânico. E, a seguir, Caminhoá apresentou as divisões daquele último: 
Recapitulando, e partindo do todo para as partes, a natureza possui o Império orgânico, que consta de 2 Reinos - o animal e o vegetal: este é formado por 3 grandes Ramos: dicótilos, monocótilos e acótilos; cada um dos quais possui várias Classes; estas são compostas de Famílias; e as famílias constam de Tribos. Estas de Gêneros; estes de Espécies, as quais são a reunião de indivíduos. (Idem. Ibidem, p. 1584)

A taxonomia e toda a pesquisa que a envolve são de suma importância para a História Natural, em especial para a Botânica. A enorme pluralidade das plantas desperta o interesse em entendê-las e, para que isso seja realizado de maneira mais fácil, foi necessário que houvesse uma organização dos seres para que não fossem confundidos uns com os outros. E, para tal, Caminhoá informou que se basearia no estudo do império orgânico, reino vegetal, classes, famílias, gêneros e espécies.

Dando sequência, o botânico avança para o ponto em que trata Das Classificações em Particular. Assim como destacado anteriormente, a análise de Caminhoá nos revela as maneiras que os especialistas da área encontraram de organizar seus estudos, o que consequentemente facilitou tal processo.

Os caracteres botânicos são aqueles que os autores definiram por serem fornecidos pelos diferentes órgãos das plantas. Portanto, são os formadores da base de uma classificação, encaminhando para o maior detalhamento da composição dos seres em questão.

Levando em consideração determinados sinais observados pelo fato dessas características estarem presentes ou não, os estudiosos nomearam por constantes, raros, positivos ou negativos. São dominantes aqueles que são constantes e também positivos, ganhando destaque sobre os demais, o que torna essa classificação de suma importância, fazendo com que alguns especialistas a observem pela chamada lei da subordinação ou correlação dos caracteres. Tem maior importância os caracteres que são mais geralmente encontrados, assim como o grau de sua participação na função do órgão em que é localizado. Com o objetivo de se fazer mais claro, Caminhoá relata:

Para exemplificar, lembramos, que de todos os órgãos aquele para o qual todos os outros concorrem, é o embrião; por cujos motivos, os caracteres e as modificações que nele se notam são de primeira importância; e algumas delas são de uma constância inexcedível; por exemplo, sua forma, direção, etc. (Idem. Ibidem, p. 1586)

As grandes divisões dos vegetais são baseadas nas características do embrião, sendo ele o ponto de partida para a organização e forma da futura planta, destacando-se por ser uma característica de $1^{a}$ ordem. Em seguida, observando a flor e os órgãos originados a partir dela, destaca-se a semente por ser classificada como $2^{a}$ ordem. A partir dos números, situações e proporções, entende-se os estames como $3^{a}$ ordem. Já as folhas e inflorescências encaixam-se nos caracteres de $4^{a}$ ordem. 
Lançando mão das ideias de ordem apresentadas anteriormente, a última é utilizada pela maioria dos autores como a determinadora das espécies. Por sua vez, a $3^{\mathrm{a}}$ ordem serve para definir os gêneros, a $2^{\mathrm{a}}$ ordem para classificar as famílias, e os de $1^{\mathrm{a}}$ ordem para caracterizas as classes e ramos.

Caminhoá informa que o professor Silver d'Aberdeen resumiu essa parte de forma brilhante, mesmo sendo uma das mais importantes e difíceis da História Natural. Segue a síntese:

\begin{abstract}
As espécies baseiam-se nas particularidades dos órgãos vegetativos (como folhas, etc.); os gêneros baseiam-se nos caracteres tirados do perianto (cálice e corola), e nos caracteres exteriores do fruto; as ordens ou famílias fundam-se na estrutura do ovário e suas relações com os envoltórios florais; as classes fundam-se nas particularidades da semente, principalmente nas do embrião; os ramos baseiam-se na presença, ausência e número das cotilédones segundo uns. Para outros, relaciona-se com o predomínio exclusivo de certos tecidos ou elementos histológicos como células, fibra e vasos. Entre cada tipo superior e o inferior há sempre uma gradação insensível. (Idem. Ibidem, p. 1586)
\end{abstract}

A parte seguinte do texto tem como título Nomenclatura Botânica, tratando, portanto, da parte de qualquer ciência que trata da linguagem técnica, sendo então mais um passo de suma importância para a organização e simplificação do que estamos tratando aqui. A nomenclatura superou as dificuldades que existiam no momento de nomear aos seres estudados.

Caminhoá argumentou que existiram diferentes tipos de nomenclaturas, que foram abandonadas, e a que vigora nos dias atuais é a chamada binária. Em relação à esta última, o crédito deve ser dado a Carl Von Lineu pelo feito racional que muito facilitou o trabalho das classificações. Recebe esse nome pelo fato de se dar dois nomes para cada tipo: um genérico e um adjetivo. O primeiro deve ser um substantivo que indique o nome do gênero, escrevendo com letra maiúscula. Já o segundo, o nome da espécie, deve indicar uma qualidade ou propriedade da planta em questão, além de ser escrito com letra minúscula, com exceção daqueles que sejam em homenagem a algum botânico com o intuito de perpetuar sua influência no meio, ou então indicando uma região, país ou cidade.

Ainda em relação à organização dos nomes, diferentes países reuniram-se em Paris, no âmbito da Exposição Universal de 1867, e por convite do governo francês, botânicos de diversos países reuniram-se no $1^{\circ}$ Congresso Internacional de Botânica com o objetivo de discutir e legislar sobre "o abuso de criar-se gêneros e espécies novas, sem que houvesse razão”, e para assim acabar com tais abusos. Foi então encarregado pelo congresso o professor Alphonse Louis Pierre Pyrame de Candolle (1806-1893) para formular o projeto de leis concernentes à nomenclatura botânica. Após o debate, foram aprovados artigos que não podem ser impunemente violados.

O documento aprovado tem como título Leis Relativas à Nomenclatura Botânica, Segundo o Congresso Internacional de Paris, redigido no ano de 1876, elaborada por Alphonse de Candolle, 
sendo considerado o primeiro autêntico Código internacional de Nomenclatura Botânica, conhecido também como Código de Paris. (Rodrigues, 2003)

$\mathrm{Na}$ introdução do documento, informa-se que o sistema de nomenclatura dos seres organizados criado por Lineu estava decaindo, após ser considerada o mais admirável até meados do século XIX. Segundo informe do documento, quanto à nomenclatura, causava inquietação o grande aumento de nomes, principalmente genéricos e específicos. E, prosseguia: "O Sr. Carlos Kock e vários outros botânicos empreenderam uma verdadeira cruzada, para que os jardineiros, em geral ignorantes do latim e da parte clássica da Botânica, não continuassem a estropiar toda a nomenclatura." (Idem. Ibidem, p. 1587)

Segundo o documento, Lineu e seus sucessores procuravam simplificar a tecnologia botânica. Diversos naturalistas vinham procurando realizar uma reforma filosófica naquele sentido. Cada especialista dava mais importância a este ou aquele ponto, faltando assim um entendimento comum a todos. Lineu defendia que em limitados casos deveria ser permitido criar um gênero. Por sua vez, De Candolle defendia o respeito aos nomes criados anteriormente por acreditar que, na maioria dos casos, tinham sido dados por antigos botânicos. Contudo, reforçava o documento, no momento atual a grande questão básica é a da espécie.

Após a realização do congresso e a resolução de novas normas para a nomenclatura na botânica, o número de sinônimos diminuiu consideravelmente. A razão para tal, residia "não só ao reconhecimento das leis ali decretadas, como nos meios mais perfeitos de investigação. Além disso, quanto aos gêneros, a proporção dos novos decresce; enquanto que o das espécies aumenta, mas de um modo descomunal!”. (Idem. Ibidem, p. 1589)

O primeiro capítulo das resoluções do Congresso de Paris foi intitulado "Disposições Gerais". O primeiro artigo dispõe que a História Natural não pode evoluir sem um sistema regular de nomenclatura, que fosse reconhecido e empregado pelos naturalistas dos diversos países. As regras da nomenclatura deveriam ser baseadas em motivos claros e fortes, para que cada um os compreendesse e aceitasse, e deveria se evitar, ou repetir o emprego de formas e de nomes, que pudessem produzir erros, ou trazer a confusão à ciência. Também deveria ser evitada toda a criação de nomes inúteis. Decretava-se que nenhum uso contrário das regras poderia ser mantido, bem como os princípios e as formas da nomenclatura deveriam ser os mais semelhantes em Botânica e Zoologia.

Os artigos sexto e sétimo definiram as regras da nomenclatura:

Art. $6^{\circ}$ - Os nomes científicos são em língua latina...

Art. $7^{\circ}$ - A nomenclatura compreende das categorias de nomes: $1^{\circ}$ Nomes, ou antes, termos que exprimam a natureza dos grupos compreendidos uns nos outros; $2^{\circ}$ Dos nomes particulares à cada um dos grupos de plantas, ou de animais, que a observação faz conhecer. (idem. Ibidem, p. 1589) 
Caminhando para o segundo capítulo, definiu-se o modo de designar a natureza e a subordinação dos grupos que integram o reino vegetal. $\mathrm{O}$ artigo oitavo definiu que todo indivíduo vegetal pertence a uma espécie, toda espécie a um gênero, esse a uma família, uma família a uma coorte e toda coorte a uma classe. Por sua vez, o artigo nono estabeleceu que se reconhecia em diversas espécies também variedades e variações, em certas espécies cultivadas, modificações mais numerosas ainda, em muitos gêneros seções, e em muitas famílias tribos. Dessa maneira, o todo dos grupos subordinados - que não podem ser invertidos de maneira alguma- se dá começando pelo Reino Vegetal, seguido da Classe, subclasse, coorte, subcoorte, ordem/família, subordem/subfamília, tribo, subtribo, gênero, subgênero, seção, subseção, espécie, subespécie/prole/raça, variedade, subvariedade, variação, subvariação, planta.

Ainda no segundo capítulo, no décimo segundo artigo, foi definido que a fecundação de uma espécie por outra espécie cria um híbrido. Por sua vez, a de uma modificação de uma subdivisão da espécie por uma outra modificação da mesma espécie, cria um mestiço. A classificação das espécies em uma sub-divisão de gênero deveria se fazer por meio de sinais tipográficos, letras, ou cifras. E, por fim, determinava-se que as modificações das espécies cultivadas deveriam se prender à espécies espontâneas donde se derivariam.

Partindo para o terceiro capítulo, intitulado Da Maneira de Designar Cada Grupo ou Associação de Vegetais em Particular. Divididos em sete seções, os botânicos definiram os princípios gerais; nomenclatura dos diversos grupos; publicação, data e combinação dos nomes; precisão aos nomes pela citação do botânico que publicou antes; nomes conservados, divisão dos grupos, modificação, transporte, elevação ou rebaixamento ou quando dois grupos da mesma ordem se reúnem; nomes rejeitados, mudados ou modificados e nomes de plantas nas línguas modernas.

Em primeiro momento, acerca dos princípios gerais, os artigos definem que cada grupo natural de vegetais não pode ter mais de uma designação válida ou aceitável, seja ela dada por Lineu ou pela nomenclatura acordada pelos botânicos posteriormente. A não ser por um motivo de relevante gravidade, o nome não deve ser alterado, assim como sua combinação. Por fim, é definido que a forma, o número e arranjo dos nomes dependem da natureza de cada grupo.

A segunda seção desenvolve as questões sobre a nomenclatura dos diversos grupos. Os nomes dados às classes e sub classes são baseados em um dos principais caracteres, sendo expressos por palavras gregas ou latinas, dando aos respectivos grupos da mesma natureza uma harmonia. Os coortes e sub-coortes recebem o nome de acordo com as principais famílias com a desinência em "ales". Por sua vez, as famílias são designadas por um de seus gêneros com a desinência em "aceas”. Já as tribos e sub tribos tiram o nome dos gêneros que dela fazem parte, junto da desinência “eas" ou "eeas". E, os 
gêneros, suas divisões, superiores e espécies recebem nomes substantivos, que são para cada um deles como os nossos nomes próprios de famílias.

Por sua vez, os híbridos e subdivisões das espécies têm seus nomes definidos pelo gênero ao qual pertencem, seguido de um nome específico, tendo como origem um adjetivo, tendo que indicar algo de sua aparência, característica de origem, história ou propriedades.

Seguindo para a seção de número três, vemos as definições para datas e combinações. A data de um nome ou sua combinação é a sua publicação efetiva. Uma espécie não é considerada classificada caso não tenha nomes genérico e específico, assim como também não é dispensável os respectivos complementos.

A precisão dos nomes pela citação do botânico que os publicou antes é analisada na seção quatro. É preciso citar o nome do autor que primeiro publicou o nome ou a combinação dos nomes de que se trata, para ser exato e completo na indicação do nome ou dos nomes de um grupo qualquer. Os nomes publicados, segundo um documento inédito, são precisados pela adição do nome do autor que publica.

Quanto à conservação de nomes, temos a seção cinco. O quinquagésimo terceiro artigo define que uma mudança de características ou uma revisão que acabe por excluir certos elementos de um grupo ou adições de novos elementos não permitem que ocorra a mudança do nome ou nomes do grupo. Quando o gênero é dividido em mais de duas partes, o nome deve ser conservado e dado uma das divisões principais. Caso ocorra a reunião de dois ou mais grupos de uma mesma natureza, conservase o nome mais antigo e, se forem da mesma data, o autor escolhe. Quando se divide uma espécie em duas ou mais, é mantida a mais antiga.

A penúltima seção que trata dos nomes que devem ser rejeitados, mudados ou modificados é composta por artigos que definem que ninguém está autorizado a mudar um nome com a justificativa de que outro seria melhor.

Por fim, a seção sete trata Dos Nomes das Plantas nas Línguas Modernas. De acordo com o sexagésimo sétimo artigo, os botânicos empregam nas línguas modernas os nomes científicos latinos, ou aqueles que deles derivam-se imediatamente. E, o seguinte, determina que os botânicos devem ser contrários à introdução de uma língua moderna de nomes (de plantas) que nela não existam. Com exceção, se forem derivados do nome botânico latino, com alguma pequena modificação.

$\mathrm{Na}$ sequência da obra, Caminhoá apresentou as definições de classes, famílias, gêneros, espécies, variedades, raça, indivíduos, sinônimos e nomes dos botânicos.

O primeiro deles foi a definição de classes, "são grupos de famílias, tendo caracteres comuns que as fazem parecer entre si”. (Idem. Ibidem, p. 1597). 
Por sua vez, quanto às famílias, Caminhoá argumentou que são os "gêneros dos gêneros". Ele argumentou que para grande número de fitologistas, ordem e família, em Botânica, são sinônimos. Contudo, para outros, há diferença tecnológica entre aquelas duas expressões científicas. O autor lembrou que até as decisões dos congressos botânicos de Paris e de Genebra, entre outros, não havia regras estabelecidas a respeito. Contudo, tais regras já existem.

A seguir, definiu os gêneros. Estes "são os grupos ou a reunião de espécies com certos caracteres também comuns. O número dos gêneros conhecidos tem sido crescente de um modo espantoso!" (Idem. Ibidem, p. 1597)

A seguir, passou para a espécie. Caminhoá iniciou argumentando que não é coisa tão fácil decidir se tal tipo é ou não uma espécie nova ou distinta das outras.

Para o autor, a noção de espécie é capital.

Caminhoá argumentou que em virtude da forma pela qual a espécie é considerada, surgiram duas escolas biológicas.

A primeira é a que defende a pluralidade das espécies. Para esta, cada espécie só pode produzir indivíduos da mesma espécie, desde o aparecimento dos primeiros seres sobre a Terra, até os dias de hoje. Dentre os defensores dessa corrente encontram-se Louis Agassiz (1807-1873), Constantin James (1813-1888), William Balfour Baikie (1824-1864), Alphonse Wood (1810-1881), entre outros.

Por sua vez, a segunda escola defende a unidade das espécies, ou seja, “considera que uma só espécie, ou, quando muito, um pequeno número, basta para, em virtude de sucessivas modificações devidas ao clima, à nutrição, à domesticação, ao cruzamento com outras espécies, etc., podem perfeitamente da origem a todas as demais conhecidas". (Idem. Ibidem, p. 1600) De acordo com Caminhoá, Lamarck e Darwin são os "fundadores e defensores desta escola". (Idem. Ibidem, p. 1600)

A seguir, Caminhoá passou a tratar dos conceitos de variedade, raça, variação, entre outros. Assim os definiu:

Quando um número de indivíduos da mesma espécie apresenta certas diferenças entre si, que não são comuns a todos, diferenças, que ora são devidas a circunstâncias ocasionais, ora ao cruzamento com indivíduos de outra espécie, etc., dá-se um conjunto de circunstâncias que convém mencionarmos:

Ou os novos caracteres e modificações persistem, e se transmitem por semente, o que equivale a dizer - por fecundação; e nesse caso há o aparecimento de uma raça nova;

Ou tais características persistem durante um certo número de gerações; porém sempre com tendência a desaparecerem; e, na máxima parte dos casos, não se transmitem por fecundação; e então há o que os naturalistas denominam variedade;

Ou essas modificações não se transmitem absolutamente, e são observados apenas no indivíduo que as sofreu; e então são conhecidas na ciência pelo nome de variação. (Idem. Ibidem, p. 1600) 
Dando sequência, Caminhoá se centra na definição de indivíduo. Para o autor, o "indivíduo" é uma das classificações que dividem as opiniões dos estudiosos da área. Ele apresenta duas destas perspectivas. Para Joseph Dalton Hooker (1817-1911), pode ser definido por todo e qualquer espécie que tenha vida própria. Já para Braun, indivíduo é aquele que teve origem de uma semente.

A seguir, passou a apresentar considerações sobre os sinônimos.

Segundo Caminhoá, uma das razões que produzia o descontentamento naqueles que estudavam a Botânica era o "grande número de nomes científicos, e sinônimos que tinha cada planta". (Idem. Ibidem, p. 1602) E, apresentou a origem desse equívoco:

\begin{abstract}
Isso provinha ordinariamente da falta de publicidade dos estudos dos diferentes botânicos; cada um dos quais dava um nome à mesma planta; e do grave inconveniente de não haverem bases estabelecidas, e aceitas, como hoje; de modo que naqueles tempos cada um considerava o assunto pelo modo que melhor parecia.

Outros, posto que em menor número, de propósito davam nomes novos a plantas que eles sabiam já estarem classificadas por colegas muito competentes; e isto só com o fim de verem seu nome figurando na sinonímia entre os que classificaram o tipo. Isso infelizmente, ainda hoje é praticado por alguns! (Idem. Ibidem, p. 1602)
\end{abstract}

Para evitar os inconvenientes apresentados supra por Caminhoá, foram então estabelecidas “normas em relação à sinonímia". (p. 1602)

O autor apresenta como exemplo a árvore da borracha ou seringueira do Pará. Segundo ele, é conhecida "pelo nome científico: Hevea Guyanensis Aubl.; e tem por sinônimos: Siphonia elástica Persoon, Siphonia Guianensis A. Jussieu, Jatropha elástica Linneu, e Sihonia cahuchu Richard, etc.” (Idem. Ibidem, p. 1603)

Os nomes das plantas podem vir acompanhados dos nomes dos botânicos que as classificaram, normalmente abreviados, ou seja, escrevem-se as primeiras letras da palavra. Quando os botânicos são conhecidos por já terem classificado diversos vegetais, compreende-se facilmente a abreviação. Quando não, se torna mais difícil saber de quem se trata. Por isso, indica-se que se tenha um livro para consultar os nomes completos dos respectivos estudiosos citados. Visando exemplificar tal fato, Caminhoá apresentou um quadro de abreviações dos nomes de botânicos entre as páginas 1603 e 1605 de sua obra.

Após esclarecer as questões acerca da nomenclatura, Caminhoá traz em sua obra a exposição dos métodos e sistemas de classificação. Apresenta, portanto, os que recebem maior destaque ou por originalidade ou por terem servido de base para outros. Nomes como Lamark, Piton de Tournefort, Lineu, Jussieu, Endlieher, De Candolle, Lindley e Brogniart estão presentes em sua lista, além de ilustrar as ideias através de mapas dos respectivos métodos. 
Para Caminhoá, o primeiro nome a merecer destaque é o de Joseph Pitton de Tournefort (16561708), estudioso francês que teve como base de suas análises a flor, e particularmente a colora, seja em relação à sua presença ou ausência, e forma e inserção. Para sua época, final do século XVII, e para as plantas disponíveis para seu estudo, o método fazia sentido. No entanto, informou Caminhoá, era já incompleta. Ao longo da página 1606, o autor apresentou um mapa com o sistema de classificação elaborado pelo naturalista francês. Por fim, Caminhoá esboça uma crítica ao referido sistema:

Esta classificação peca: $1^{\circ}$ porque distinguiu as árvores das ervas, quando na natureza existem promiscuamente no mesmo gênero e espécie plantas herbáceas e arborescentes; $2^{\circ}$ porque supunha sem flores as plantas Apetalas, e as Amentaceas que realmente possuem flores aperiantadas; $3^{\circ}$ porque repetia como classes distintas as Rosaceas, por serem umas arborescentes e outras herbáceas: o mesmo diremos das Papilionaceas, e das Apetalas, etc. (Idem. Ibidem, p. 1606)

Dando sequência, temos o sistema organizado por Carl von Lineu, botânico altamente reconhecido e valorizado por Caminhoá. O ilustre estudioso foi quem estabeleceu as classificações que serviram de base para as modernas, ocupando o papel de um gênio observador. A partir de sua organização e simplificação, a nomenclatura binária ganhou espaço. Informa que foram as flores os órgãos básicos da classificação lineana, em particular os estames e carpelos, por terem "caracteres muitos mais fixos, do que os da corola". (Idem. Ibidem, p. 1607) O mapa do sistema de classificação do naturalista sueco se faz presente na página 1607.

A seguir, Caminhoá apresentou o sistema de classificação proposto por Jean-Baptiste-Pierre-

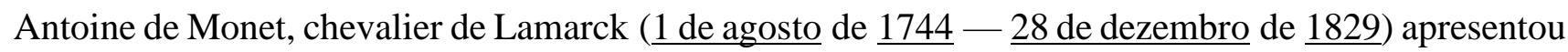
uma nova visão acerca dos seres vivos, ou seja, defendia que as espécies vegetais e animais existentes atualmente vieram de outras espécies que existiram antes no tempo. Antes dessa época, acreditava-se que as espécies eram fixas. Segundo Caminhoá, com relação à Botânica, foi responsável por criar a chave dicotômica, onde orientava a maneira de atingir a determinação de um tipo de vegetal. Nesta chave, diferencia-se as características de dois em dois, onde um é positivo e, o outro, negativo. Cada um deles é dividido novamente em outros dois, positivo e negativo e assim sucessivamente.

A seguir, Caminhoá comentou sobre o método natural do francês Antoine-Laurent de Jussieu (1748-1836). Este último, segundo Caminhoá, reconheceu que o sistema de Lineu era insuficiente e inexato. Buscando base no maior número possível de caracteres fornecidos pelas plantas, Jussieu observou os cotilédones e as sementes, seguindo daí para o estudo da corola. Esse maior aprofundamento permitiu que o botânico encontrasse mais elementos que Lineu, afinal o uso do microscópio também estava bem mais aperfeiçoado no período de Jussieu. Para maiores detalhes, Caminhoá expôs o mapa do método natural de Antonio Lourenço na página 1608, que se divide em acotilédones, monocotiledôneos, e dicotiledóneos. 
Augustin Pyramo de Candolle (1778-1841) também apresentou seu sistema de classificação. Segundo Caminhoá, Candolle iniciou por diferenciar as plantas que são formadas apenas de células, sem apresentar fibras, nem vasos, denominando-as de celulares. A seguir, apresentou as que possuíam vasos, chamando-as vasculares. Ademais, notou que há plantas que são floríferas, e possuem sementes com embrião, nomeando-as de fanerógamas. Por sua vez, há aquelas que não são floríferas, e se reproduzem por esporos, não tendo, portanto, embrião, e denominou-as de criptógamas. A classificação de Candolle está disponível na página 1609.

Dando sequência, Caminhoá comentou sobre o sistema de classificação de Stephan Ladislaus Endlicher (1804 - $\underline{1849})$. O botânico austríaco redigiu a obra Genera Plantarum (1836), na qual apresentou seu sistema de classificação. Segundo Caminhoá, Endlicher dividiu as plantas em dois grupos, e a seguir comentou:

$1^{o}$ daquelas, cujos eixos e apêndices não apresentam diferença, ou melhor, das que não têm caule, nem folhas propriamente ditas, as quais denominou Talófitas, compreendendo os acótilos celulares.

$2^{\circ}$ daquelas, cujos eixos (caules, ramos, etc.) são distintos das folhas; compreendendo os acótilos vasculares, os monocótilos e os dicótilos.

Não é uma classificação sem defeitos, pois ele reuniu no segundo grupo tipos muito distintos, não só por seu porte, como pela estrutura de suas diferentes partes, como, enfim, por terem uns ausência de cotilédones e de flores, outros apenas uma cotilédone e flores, e outros duas cotilédones e também flores. (Idem. Ibidem, p. 1610)

A seguir, Caminhoá comentou sobre o sistema de classificação de John Lindley (1799-1865). O naturalista inglês tomou como ponto de partida de sua classificação a ausência ou presença da flor. Ele dividiu as plantas em floríferas e não floríferas. As floríferas foram divididas em cinco tipos:

$1^{\circ}$ Rizógenas, aquelas, cujos órgãos da reprodução se desenvolvem de um thallo (como nas Raflesiaceas).

$2^{\circ}$ Endógenas, as que têm uma só cotilédone, folhas retinervias e o lenho mais novo centro (como as palmeiras).

$3^{\circ}$ Dtctiógenas, as que apresentam uma só cotilédone, as folhas

$4^{\circ}$ Exógenas, as que têm cotilédones, folhas de nervuras reticuladas, o lenho mais antigo no centro, e sementes cobertas (como as Dicotiledóneas, em geral).

$5^{\circ}$ Gimógenas, que têm 2 cotilédones também, folhas de nervuras reticuladas, lenho mais antigo no centro, e sementes nuas (como, por exemplo, os pinheiros etc.) (Idem. Ibidemp. 1610)

Já as que não possuem flores, foram divididas por Lindley da seguinte forma:

Tallógenas, as que não apresentam caule ou eixo visível (como as algas etc.)

Agrógenas as que têm caule e folhas distintas (como os fetos e vários outros) (Idem. Ibidem p. 1610) 
Por fim, Adolphe Théodore Brongniart (1801 - 1876) compôs a relação de naturalistas de destaques de Caminhoá. O admirado botânico criou sua classificação a partir dos vegetais do Jardim de Plantas de Paris, entendendo a existência de sessenta e oito classes, duzentos e noventa e seis famílias, e demais divisões. Visando fornecer maiores detalhes, Caminhoá colocou em sua obra um mapa sobre o método de Brogniart, presente na página 1611, dividida em criptógamas e fanerógamas.

Para finalizar, Caminhoá informou que o sistema de classificação mais seguido é o de AdrienHenri de Jussieu (1797-1853), e apresentou a série de natural de famílias vegetais conforme o naturalista francês dispôs. O método de classificação de Jussieu dividiu-se em: criptógamas ou acotiledôneas, e a das fanerógamas monocotilédones e fanerógamas dicotilédones. E, a seguir, apresentou a classificação das plantas segundo o professor Julio Von Sachs (1832-1897). Este último apresentou o seu sistema de classificação da seguinte forma: Talófitas, Caraceas, Muscineas, Criptógamas Vasculares, e Fanerógamas.

\section{CONSIDERAÇÕES FINAIS:}

A análise do capitulo Taxonomia da supra obra de Caminhoá nos revela a atualização do pensamento científico do autor, e a sua conexão com o debate das questões botânicas contemporâneas. Observamos um conjunto de autores que o botânico menciona para basear as suas ideias, bem como aqueles que ele refuta. E, observamos que o mesmo tem conhecimento dos diversos sistemas de classificação, sejam aqueles de autores de séculos anteriores, bem como daqueles de naturalistas contemporâneos ao período em que atuou. Caminhoá tratou de diversos temas como as classificações, a discussão sobre a origem das espécies, a nomenclatura botânica, os métodos e sistemas de classificação, entre outros temas. Foi um botânico antenado com as questões científicas que marcaram o seu tempo, e sua obra constitui-se como uma fonte importante para o processo de emergência e consolidação das ciências naturais no Império do Brasil. 


\section{REFERENCIAS}

\section{Textos de Joaquim Monteiro Caminhoá:}

CAMINHOÁ, Joaquim Monteiro. Introdução. In: Elementos de Botânica Geral e Médica. Vol. 1. Rio de Janeiro: Tipografia Nacional, 1877.

CAMINHOÁ, Joaquim Monteiro. Taxonomia. In: Elementos de Botânica Geral e Médica. Vol. 2. Rio de Janeiro: Tipografia Nacional, 1877, pp. 1575-1620.

\section{Artigos, Livros e Teses:}

ALONSO, Angela. Idéias em Movimento. A Geração 1870 na Crise do Brasil-Imperio. São Paulo: Paz e Terra, 2002.

CARMO, Viviane Arruda do; BIZZO, Nélio; MARTINS, Lilian Al-Chueyr Pereira. Alfred Russel Wallace e o Princípio da Seleção Natural. Filosofia e História da Biologia, v. 4, pp. 209-233, 2009.

Casa de Oswaldo Cruz / Fiocruz. Dicionário Histórico-Biográfico das Ciências da Saúde no Brasil (1832-1930). Verbete Escola Anatômica, Cirúrgica e Médica do Rio de Janeiro. In: http://www.dichistoriasaude.coc.fiocruz.br (Acessado no dia 17/06/2021).

EDLER, Flavio Coelho. Ensino e Profissão Médica na Corte de Pedro II. São Paulo: Editora UFABC, 2014.

MAYR, Ernest. O Desenvolvimento do Pensamento Biológico. Diversidade, Evolução, e Herança. Brasília: Editora Universidade de Brasília, 1998.

PESTRE, Dominique. Por uma nova história social e cultural das ciências: novas definições, novos objetos, novas abordagens. Cadernos IG/Unicamp. Campinas, v.6, n.1, 1996.

RAJ, Kapil. Conexões, Cruzamentos, Circulações. A Passagem da Cartografia Britânica Pela Índia, Séculos XVII-XIX. Cultura [on-line], vol. 24, 2007. In: http: //journals.openedition.org/cultura/877 (acessado no dia 14 de agosto de 2021)

RAJ, Kapil. Além do Pós-Colonialismo... e Pós-positivismo. Circulação e a História Global da Ciência. Revista Maracanan. Rio de Janeiro, n. 13, dezembro de 2015, pp. 164-175. DOI: http://dx.doi.org/10.12957/revmar.2015.20133 (acessado no dia 14/08/2021)

RODRIGUES, W. A. Revisão da nomenclatura botânica: datas importantes na história da nomenclatura botânica pós-linneana. UEPG Biol. Health Sci.. Ponta Grossa, v. 9, n. 3/4, set./dez. 2003, p. 73-82.

VARELA, Alex Gonçalves. Joaquim Monteiro Caminhoá: um médico ilustrado do Império do Brasil, 1858-1896. História, Ciências, Saúde - Manguinhos. Rio de Janeiro, v.26, n.1, jan.-mar. 2019, pp.335345.

VARELA, Alex Gonçalves; VIEIRA, Gabriel; PEREIRA, João Marcos Rocha (Orgs.). Um Botânico no Império do Brasil: a Trajetória de Joaquim Monteiro Caminhoá (1858-1896). Rio de Janeiro: Quártica, 2021. 